\title{
Farklı çinko form ve dozlarının mısırın kuru madde verimi üzerine etkisi
}

\section{Effect of zinc forms and doses on dry matter yield of maize}

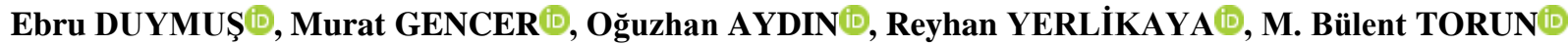 \\ Çukurova Üniversitesi, Ziraat Fakültesi, Toprak Bilimi ve Bitki Besleme Bölümü, 01330, Adana \\ Sorumlu yazar (Corresponding author): E. Duymuş, e-posta (e-mail): ebruduymus@yahoo.com.tr \\ Yazar(lar) e-posta (Authore-mail): mrtgncr50@gmail.com,oguzhanaydiin@gmail.com, yerlikayarengin@gmail.com, mbtorun@cu.edu.tr
}

\section{MAKALE BİLGİSİ}

Alınıș tarihi 21 Ekim 2019

Düzeltilme tarihi 21 Ekim 2019

Kabul tarihi 14 Ocak 2020

\section{Anahtar Kelimeler:}

Çinko formu

Uygulama dozu

Çinko noksanlığ

Kuru madde verimi

Misir

\begin{abstract}
ÖZ
Çinko eksikliğinden kaynaklı bitkisel verimde önemli düşüşlerin olduğu bildirilmiştir. Bu düşüşlere karş1lık alınabilecek en etkin yöntemlerden bir tanesi $\mathrm{Zn}$ gübrelemesidir. Bitkinin $\mathrm{Zn}$ kullanım etkinliğinde, uygulanan gübrenin $\mathrm{Zn}$ dozu ve formunun önemli olduğu düşünülmektedir. Bu amaçla, sera koşullarında artan dozlarda [0 (kontrol), $\left.0.2,1,5 \mathrm{mg} \mathrm{kg}^{-1}\right]$ ve farklı formlarda $\left(\mathrm{ZnO}, \mathrm{ZnSO}_{4} .7 \mathrm{H}_{2} \mathrm{O}, \mathrm{Zn}\right.$-EDTA, $\left.\mathrm{ZnCl}_{2}\right) \mathrm{Zn}$ uygulamalarının mısır bitkisinin büyüme, yeşil aksam SPAD değeri, kuru madde verimi, Zn konsantrasyonu ve Zn içeriği üzerine etkisi belirlenmiștir. Denemede elde edilen bulgulara göre, $\mathrm{Zn}$ noksanlığından kaynaklı verim kayıplarının olduğu buna karşılık $\mathrm{Zn}$ uygulamasının söz konusu verim kayıplarının önüne geçtiği saptanmıştır. Çinko uygulamasından kaynaklı verim artış oranlarının \%9 ile \%191 arasında değiştiği, kontrol uygulamasına göre en belirgin artışların 1 ve $5 \mathrm{mg} \mathrm{kg}^{-1} \mathrm{Zn}$ uygulamalarında olduğu bulunmuştur. Bu artış oranları üzerine uygulanan $\mathrm{Zn}$ formunun da önemli olabildiği belirlenmiștir. Özellikle en düşük Zn uygulama dozu olan 0.2 $\mathrm{mg} \mathrm{kg}^{-1}$ 'da kontrol uygulamasına göre ZnO'den kaynaklı yeșil aksam kuru madde verim artışı $\% 11$ elde edilirken bu değer $\mathrm{Zn}$-EDTA, $\mathrm{ZnCl}_{2}$ ve $\mathrm{ZnSO}_{4} .7 \mathrm{H}_{2} \mathrm{O}$ için sırasılyla \%139, \%101 ve \%49 olarak saptanmıştır. Çinko uygulamaları, bitkinin yeșil aksam kuru madde veriminde olduğu gibi yeşil aksam $\mathrm{Zn}$ konsantrasyonunu da arttırmıştır. $\mathrm{Bu}$ artışlarda, Zn uygulama dozunun önemli olduğu buna karşılık uygulanan gübre formunun önemli bir farklılık yaratmadığı belirlenmiştir. Benzer bulgular bitki başına $\mathrm{Zn}$ alınım miktarında da elde edilmiştir. Sonuçlar genel olarak değerlendirildiğinde en etkin $\mathrm{Zn}$ uygulama dozunun 1 $\mathrm{mg} \mathrm{kg}^{-1}$ olduğu, bunun dışında $\mathrm{Zn}$ formları içinde bitkinin büyümesinde ve $\mathrm{Zn}$ kullanım etkinliğinde en etkin formun $\mathrm{Zn}$-EDTA olduğu, bunu sirasiyla $\mathrm{ZnCl}_{2}, \mathrm{ZnSO}_{4} \cdot 7 \mathrm{H}_{2} \mathrm{O}$ ve $\mathrm{ZnO}$ 'in izlediği görülmüştür.
\end{abstract}

\section{ARTICLE INFO}

Received 21 October 2019

Received in revised form 21 October 2019

Accepted 14 January 2020

\section{Keywords:}

Zinc form

Application dose

Zinc deficiency

Dry matter yield

Maize

\section{ABSTRACT}

Significant reductions have been reported in plant yields due to the zinc ( $\mathrm{Zn}$ ) deficiency. The $\mathrm{Zn}$ fertilization is one of the most effective methods to prevent the yield decreases. The $\mathrm{Zn}$ dose and form of the fertilizer used are assumed to be important in the $\mathrm{Zn}$ use efficiency of the plants. This study was conducted to determine the effects of increasing doses [0 (control), 0.2 , $\left.1,5 \mathrm{mg} \mathrm{kg}^{-1}\right]$ and different forms $\left(\mathrm{ZnO}, \mathrm{ZnSO}_{4} \cdot 7 \mathrm{H}_{2} \mathrm{O}, \mathrm{Zn}\right.$-EDTA, $\left.\mathrm{ZnCl}_{2}\right)$ of $\mathrm{Zn}$ applications on growth, shoot SPAD value, dry matter yield, $\mathrm{Zn}$ concentration and $\mathrm{Zn}$ content of maize plants under greenhouse conditions. The results of the experiment showed yield losses due to $\mathrm{Zn}$ deficiency, whereas $\mathrm{Zn}$ application prevented the yield losses. Yield increase ratio due to zinc application ranged from 9 to $191 \%$ and the most significant increase compared to the control application was obtained in 1 and $5 \mathrm{mg} \mathrm{kg}^{-1} \mathrm{Zn}$ treatments. The ratios of yield increase indicated the importance of applied $\mathrm{Zn}$ form. The increase in shoot dry matter yield in the lowest $\mathrm{ZnO}$ dose of $0.2 \mathrm{mg} \mathrm{kg}^{-1}$ compared to the control was $11 \%$, while this value was 139 , 101 and 49 for $\mathrm{Zn}-E D T A, \mathrm{ZnCl}_{2}$ and $\mathrm{ZnSO}_{4} .7 \mathrm{H}_{2} \mathrm{O}$ forms, respectively. Zinc applications increased shoot dry matter yield as well as shoot $\mathrm{Zn}$ concentration. Yield increases revealed the importance of $\mathrm{Zn}$ application dose, whereas the $\mathrm{Zn}$ fertilizer form did not cause a significant difference in yield. Similar findings were obtained in $\mathrm{Zn}$ uptake per plant. The results showed that the most effective $\mathrm{Zn}$ application dose was $1 \mathrm{mg} \mathrm{kg}^{-1}$, and $\mathrm{Zn}$-EDTA was the most effective form for plant growth and $\mathrm{Zn}$ use efficiency, followed by $\mathrm{ZnCl}_{2}$, $\mathrm{ZnSO}_{4} .7 \mathrm{H}_{2} \mathrm{O}$ and $\mathrm{ZnO}$, respectively. 


\section{Giriş}

Çinko (Zn) noksanlığı dünyada (Ortiz-Monasterio ve ark. 2007; Cakmak ve Kutman 2018) ve Türkiye'de oldukça yaygın görülen bir mikro besin elementi problemi olup, bu sorun, özellikle kurak-yarı kurak bölgelerdeki tahıl ekilen alanlarda ortaya çıkmaktadır (Graham ve Welch 1996; Cakmak ve ark. 2010). Dünyada ve ülkemizde yetiştiricilik yapılan tarım topraklarının mikro besin elementlerince yetersiz olması bitkisel üretimdeki verim ve kalite düşüşlerine neden olmakta ve buna paralel insan ve hayvan beslenmesi olumsuz etkilenmektedir. Genel olarak, dünyadaki $\mathrm{Zn}$ eksikliğine sahip toprakların bulunduğu alanlardaki insanlarda da yaygın Zn eksikliği olduğu yapılan çalışmalarda bildirilmiştir (White ve Zasoski 1999; Hotz ve Brown 2004; Welch ve Graham 2004; Alloway 2009; Cakmak ve ark. 2008; Dhaliwal ve ark. 2019; Signorell ve ark. 2019).

Birçok araştırıcı tarafından değişik bitki türleri ve aynı türün çeşitleri arasında $\mathrm{Zn}$ noksanlığına karşı duyarlılıkta farklılıklar belirlenmiş olup, bunlar örneğin, mısır (Özer 1999; Özgüven ve Katkat 2001), buğday (Torun ve ark. 1998; Singh ve ark. 2005; Bagci ve ark. 2007; Dhaliwal ve ark. 2009), arpa (Genç ve ark. 2004), pirinç (Quijano-Guerta ve ark. 2002), fasulye (Hacısalihoğlu ve ark. 2004), mercimek (Pandey ve ark. 2006), nohut (Khan ve ark. 1998), yonca (Grewal ve Williams 1999), sakız kabağı (Yağmur ve ark. 2002) ve biber (Güneş ve ark. 1999; Aktaş ve ark. 2006) olmak üzere birçok bitki türünü kapsamaktadır. Dünyada, buğday ve çeltikten sonra mısır insanlar tarafindan en çok tüketilen besin kaynaklarından bir tanesidir (FAO 2018). Literatür sonuçları genel olarak değerlendirildiğinde, misır bitkisinde $\mathrm{Zn}$ noksanlığından kaynaklı verim ve kalitedeki düşüşlere karşı alınabilecek önlemlerden bir tanesi de $\mathrm{Zn}$ gübrelemesidir. Ayrıca uygulanan organik ve inorganik gübre formlarının bitkilerce kullanılabilme etkinlikleri de birbirlerinden farklı olabilmektedir. Çinko hem organik hem de inorganik bileşikler olarak toprağa doğrudan uygulanabilir. Çinko sülfat, yüksek çözünürlüğü ve düşük maliyeti nedeniyle diğer inorganik formlara göre en yaygın olarak uygulanan inorganik $\mathrm{Zn}$ kaynağıdır. Çinko ayrıca $\mathrm{ZnO}$, $\mathrm{Zn}$-EDTA, $\mathrm{ZnCl}_{2}$ ve $\mathrm{Zn}$-oksisülfat formunda da topraklara uygulanabilmektedir. Yapılan çalışmalarda, genel olarak organik $\mathrm{Zn}$ gübrelerinin inorganik $\mathrm{Zn}$ gübrelerine göre agronomik etkinliğinin daha yüksek olduğu (Mortvedt 1991; Martens ve Westermann 1991) ancak, yüksek maliyeti nedeniyle Zn-EDTA'nın tahıl tarımında kullanımının sınırlı olduğu bildirilmiştir (Cakmak ve Kutman 2018).

Dünyada ve ülkemizde $\mathrm{Zn}$ gübrelemesi ile ilgili birçok çalışma yürütülmüş olup buna karş1lık mısır bitkisinin büyümesi ve veriminde farklı gübre formlarının ve uygulama dozlarının bir arada yürütüldüğü çalışmalar oldukça sınırlıdır. Bu noktadan hareketle bu çalışmayla, sera koşullarında mısır bitkisinin büyümesi ve kuru madde verimi üzerine, artan dozlarda ve farklı formlardan $\mathrm{Zn}$ uygulamalarının etkisini belirlemek hedeflenmiştir.

\section{Materyal ve Yöntem}

\subsection{Materyal}

Çalışma Çukurova Üniversitesi Ziraat Fakültesi Toprak Bilimi ve Bitki Besleme Bölümü Araştırma Seralarında, Pioneer 1571 çeşidi mısır bitkisi kullanılarak gerçekleştirilmiştir. Deneme toprağının $\mathrm{pH}$ 's1 8.35 (orta alkali), kireci \%13.2 (kireçli), organik maddesi \%1.03 (düşük), tuzu $0.12 \mathrm{mS}$ (tuzsuz), yarayışlı $\mathrm{P}$ konsantrasyonu $4.83 \mathrm{mg} \mathrm{kg}^{-1}$ (yetersiz), $\mathrm{K}$ konsantrasyonu $423 \mathrm{mg} \mathrm{kg}^{-1}$ (yeterli), DTPA ile ekstrakte edilebilir $\mathrm{Zn} 0.15 \mathrm{mg} \mathrm{Zn} \mathrm{kg}^{-1}$ (yetersiz), tekstürü ise tınlı kumdur. Topraklarda DTPA ile ekstrakte edilebilir Zn analizi Lindsay ve Norvell (1978), tekstür Bouyoucos (1951), kireç Çağlar (1949), pH, organik madde ve tuz Jackson (1959) yöntemlerine göre yapılmıştır.

\subsection{Yöntem}

\subsubsection{Sera denemesinin kurulması ve yürütülmesi}

Serada yürütülen denemede doğal Zn noksanlığına sahip (0.15 $\left.\mathrm{mg} \mathrm{kg}^{-1}\right)$ Kumlu Serisinden alınan toprak kullanılmıştır. Denemede plastik saksılara $4 \mathrm{~mm}$ elekten geçirilmiş hava kuru $3 \mathrm{~kg}$ toprak örneği tartılmıştır. Temel gübreleme olarak saksılara başlangıçta $200 \mathrm{mg} \mathrm{N} \mathrm{kg}$; $\mathrm{CaNO}_{3} .4 \mathrm{H}_{2} \mathrm{O}$ formunda, $100 \mathrm{mg} \mathrm{kg}^{-1} \mathrm{P} ; \mathrm{KH}_{2} \mathrm{PO}_{4}$ formunda, $125 \mathrm{mg} \mathrm{kg}^{-1} \mathrm{~K} ; \mathrm{KH}_{2} \mathrm{PO}_{4}$ formunda, $50 \mathrm{mg} \mathrm{kg}^{-1} \mathrm{~S}$; $\mathrm{CaSO}_{4}$ formunda, $5 \mathrm{mg} \mathrm{kg}^{-1} \mathrm{Fe}$; $\mathrm{Fe}-$ EDTA formunda uygulanmıştır. İlerleyen dönemlerde $\mathrm{N}$ uygulaması $400 \mathrm{mg} \mathrm{kg}^{-1}$,e tamamlanmıştır. Her saksıya 5 tohum ekilmiş ve sonrasında 3 bitkiye seyreltilmiştir.

Deneme; artan dozlarda (Zn0: $0 \mathrm{mg} \mathrm{Zn} \mathrm{kg}{ }^{-1}, \mathrm{Zn} 0.2: 0.2$ $\mathrm{mg} \mathrm{Zn} \mathrm{kg}{ }^{-1}, \mathrm{Zn} 1: 1 \mathrm{mg} \mathrm{Zn} \mathrm{kg}{ }^{-1}$ ve Zn5: $5 \mathrm{mg} \mathrm{Zn} \mathrm{kg}^{-1}$ ) ve farklı formlarda $\left(\mathrm{ZnO}, \mathrm{ZnSO}_{4} .7 \mathrm{H}_{2} \mathrm{O}, \mathrm{Zn}\right.$-EDTA ve $\left.\mathrm{ZnCl}_{2}\right) \mathrm{Zn}$ uygulaması olmak üzere 3 tekerrürlü bir çalışma olarak yürütülmüştür. Bitkilerin $\mathrm{Zn}$ noksanlık şiddetine ve büyüme performanslarındaki farklılıklara bağlı olarak 50 günlükken SPAD değerleri ölçülmüş ve hasat işlemi gerçekleştirilmiştir. Hasat edilen misır bitkilerinin yeşil aksam kuru madde verimi belirlenmiş ve daha sonra kuru yakma metoduna göre $200 \mathrm{mg}$ tartılarak porselen krozelerde 5.5 saat $550^{\circ} \mathrm{C}$ 'de kül firınında yakılmış yanan örneklerin üzerine $2 \mathrm{ml} \mathrm{1/3}$ 'lük $\mathrm{HCl}$ ve $18 \mathrm{ml}$ saf su eklenerek son hacim 20 ml'ye tamamlanı mavi bant filtre kağıdından süzülmüştür. Elde edilen süzüklerde $\mathrm{Zn}$ konsantrasyonları Atomik Absorpsiyon Spektrofotometre cihazında belirlenmiştir.

\section{3. İstatistiki analiz}

Araştırma verilerinin istatistiksel analizi JMP paket programında varyans analizi ile yapılmış ve ortalamalar arasındaki farkları belirlemek için \%5 önem seviyesinde LSD çoklu karşılaştırma testi kullanılmıştır.

\section{Bulgular ve Tartışma}

Sera koşullarında yürütülen denemede, artan dozlarda [0 (kontrol), 0.2, 1, $5 \mathrm{mg} \mathrm{kg}^{-1}$ ] ve farkl1 formlarda ( $\mathrm{ZnO}$, $\mathrm{ZnSO}_{4} .7 \mathrm{H}_{2} \mathrm{O}$, Zn-EDTA ve $\mathrm{ZnCl}_{2}$ ) $\mathrm{Zn}$ uygulamaları altında yetiştirilen mısır bitkisinin büyüme, yeşil aksamda klorofilin bir ifadesi olan SPAD değeri, yeşil aksam kuru madde verimi, yeşil aksam $\mathrm{Zn}$ konsantrasyonu ve yeşil aksam $\mathrm{Zn}$ içeriği üzerine etkileri belirlenmiştir.

\section{1. Çinko uygulamalarının SPAD değeri ve yeşil aksam kuru madde verimi üzerine etkisi}

Sera koşullarında yürütülen denemede artan dozlarda ve farklı formlarda $\mathrm{Zn}$ uygulamalarının bitki büyümesi üzerine önemli etkisinin olduğu görülmüştür (Şekil 1, 2). Mısır bitkisinde $\mathrm{Zn}$ noksanlığı simptomları büyümede gerileme ve boğumlar arası mesafede kısalma olarak kendini göstermiştir. Çinko noksanlığına bağlı simptom belirtilerinin Torun ve ark. (2016) ile uyumlu olduğu görülmüştür. 


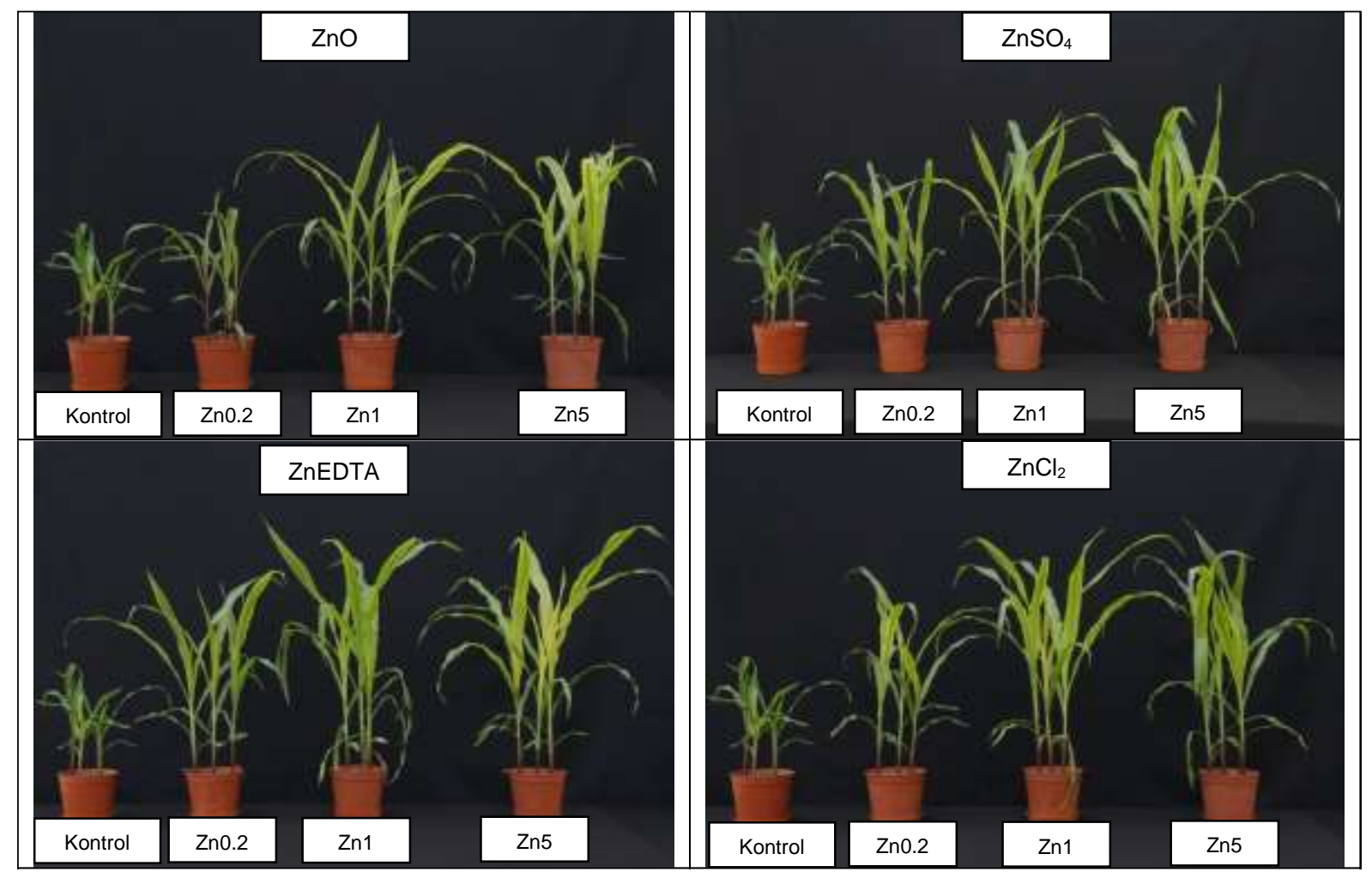

Şekil 1. Farklı formlarda $\left(\mathrm{ZnO}, \mathrm{ZnSO}_{4} \cdot 7 \mathrm{H}_{2} \mathrm{O}, \mathrm{Zn}\right.$-EDTA ve $\left.\mathrm{ZnCl}_{2}\right) \mathrm{Zn}$ uygulamalarının mısırın yeşil aksam büyümesi üzerine etkisi. Figure 1. Effects of different forms ( $\mathrm{ZnO}, \mathrm{ZnSO}_{4} .7 \mathrm{H}_{2} \mathrm{O}, \mathrm{Zn}-\mathrm{EDTA}$ and $\left.\mathrm{ZnCl}_{2}\right)$ of $\mathrm{Zn}$ applications on shoot growth of maize.

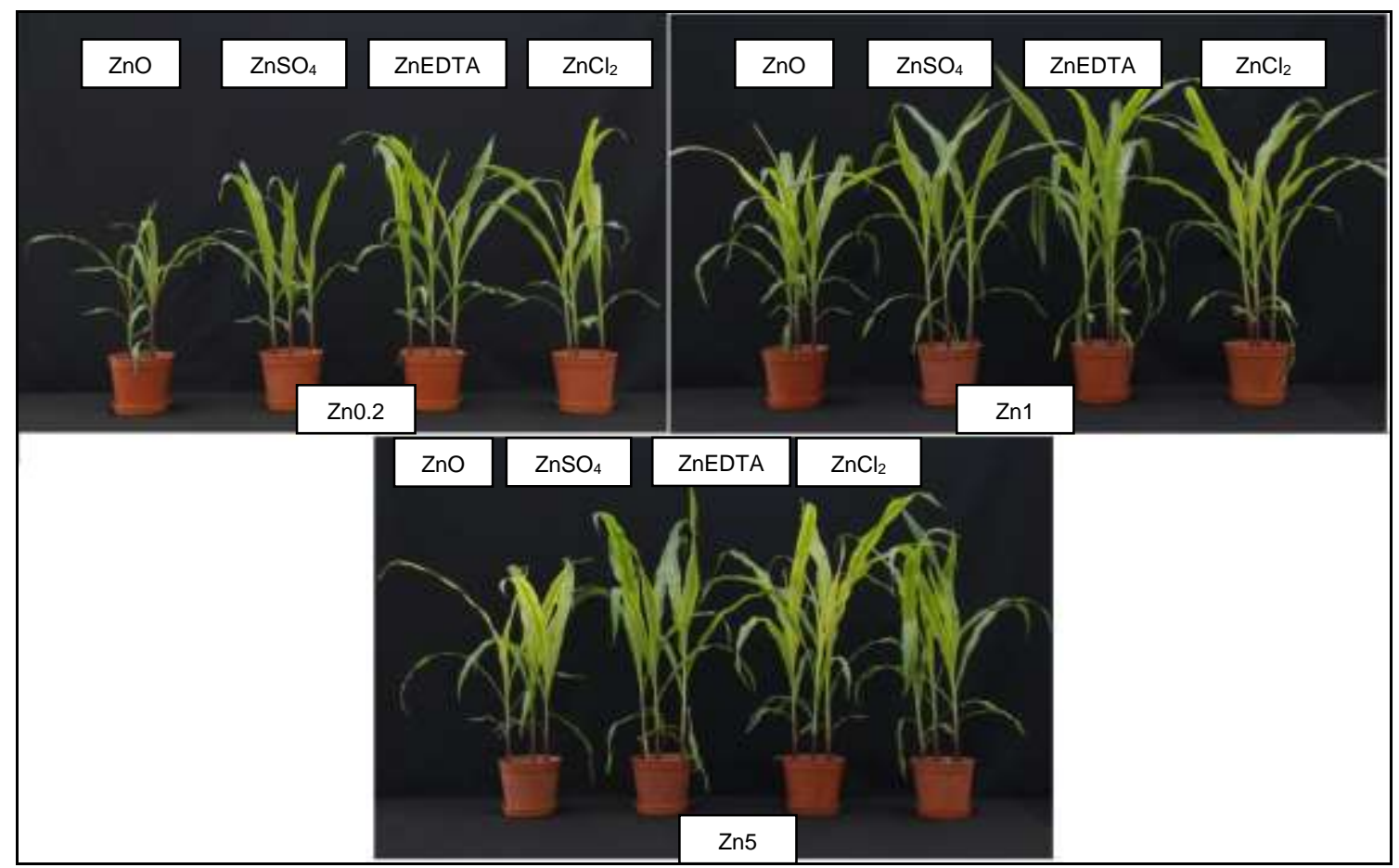

Şekil 2. Artan dozlarda (Zn0: $0 \mathrm{mg} \mathrm{Zn} \mathrm{kg}{ }^{-1}$, Zn0.2: $0.2 \mathrm{mg} \mathrm{Zn} \mathrm{kg}{ }^{-1}$, Zn1: $1 \mathrm{mg} \mathrm{Zn} \mathrm{kg}^{-1}$, Zn5: 5 mg Zn kg-1) Zn uygulamalarının mısırın yeşil aksam büyümesi üzerine etkisi.

Figure 2. Effects of increased doses (Zn0: $0 \mathrm{mg} \mathrm{Zn} \mathrm{kg}^{-1}, \mathrm{Zn0} 0.2: 0.2 \mathrm{mg} \mathrm{Zn} \mathrm{kg}^{-1}, \mathrm{Zn} 1: 1 \mathrm{mg} \mathrm{Zn} \mathrm{kg}^{-1}, \mathrm{Zn} 5: 5 \mathrm{mg} \mathrm{Zn} \mathrm{kg}^{-1}$ ) of Zn applications on shoot growth of maize. 
Denemeden elde edilen sonuçlara göre, farklı $\mathrm{Zn}$ uygulama formlarından bağımsız olarak yalnızca $\mathrm{Zn}$ uygulamaları dikkate alındığında toprağa artan dozlarda $\mathrm{Zn}$ ilavesinin bitkilerin SPAD değerleri üzerinde çok belirgin bir farklılık olmamasına rağmen kısmen düşüşe yol açtığı belirlenmiştir (Çizelge 1).

Örneğin söz konusu koşullardaki bitkilerde Zn uygulamasının yapılmadığı kontrol $(\mathrm{Zn} 0)$ uygulamasında bitkilerin ortalama yeşil aksam SPAD değerinin 34.07 olduğu ayn1 değerin $\mathrm{Zn} 0.2, \mathrm{Zn} 1$ ve $\mathrm{Zn5}$ uygulamalarında sirasıyla 29.85, 27.76 ve 27.39 olduğu saptanmıştır (Çizelge 1). Söz konusu düşüşlerin bitkilerin büyüme performanslarının farklı olmasından kaynaklı, büyüme ile seyrelme şeklinde ifade edilen büyüyen bitkilerin dokularındaki klorofil seyrelmesiyle ilişkili olduğu düşünülmüştür.

Denemede kullanılan farklı gübre formlarına bağlı olarak, artan dozlarda $\mathrm{Zn}$ uygulamalarının bitkilerin yeşil aksam kuru madde verimi üzerine istatistiksel olarak önemli etkisinin olduğu belirlenmiştir $(\mathrm{p}<0.05$; Çizelge 2$)$. Elde edilen verilere göre, bitkilerin yeşil aksam kuru madde verimlerinde, $\mathrm{Zn}$ noksanlığından kaynaklı verim kayıplarının olduğu buna karş1lık Zn uygulamasının söz konusu verim kayıplarının önüne geçtiği görülmüştür. Kontrole göre, $\mathrm{Zn}$ uygulamasından kaynaklı verim artış oranlarının \%9 (ZnO-Zn0.2) ile \%191 (ZnEDTA-Zn5) arasında değiştiği saptanmıştır. Çinko uygulamasından kaynaklı en belirgin artışların tüm formlarda kontrol uygulamasına göre $1 \mathrm{mg} \mathrm{kg}^{-1}$ ve $5 \mathrm{mg} \mathrm{kg}^{-1}$ uygulamalarında olduğu bulunmuştur. Topraklara $\mathrm{Zn}$ uygulayarak bitkisel üretimin arttırılabileceğine ilişkin birçok çalışma yapılmıştır. Erdem (2011) tarafından tarla koşullarında yürütülen, 10 farklı mısır çeşidinde $\mathrm{Zn}$ uygulamasının kuru madde verimi üzerine olan etkisini araştırdığı çalışmada toprağa $3 \mathrm{~kg} \mathrm{da}^{-1} \mathrm{Zn}$ gübrelemesiyle ortalama kuru madde verim değerinin önemli oranda arttığını ve söz konusu artışın \%21 civarında gerçekleştiğini bildirmiştir. Sera koşullarında yürütülen bir başka çalışmada Çukurova ve Niğde bölgelerine ait iki farklı toprakta $\mathrm{Zn}$ 'suz (0 $\left.\mathrm{mg} \mathrm{Zn} \mathrm{kg}^{-1}\right)$ ve $\mathrm{Zn}$ 'lu (5 $m g \mathrm{Zn} \mathrm{kg}^{-1}$ ) koşullarda yetiştirilen misır bitkisinin yeşil aksam kuru madde veriminde $\mathrm{Zn}$ uygulamasıyla verim artışı olduğu

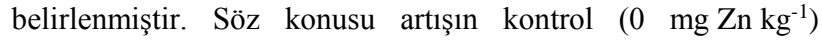
uygulamasına göre Çukurova toprağında \%174, Niğde toprağında ise \%127 düzeyinde meydana geldiği bildirilmiştir (Torun ve ark. 2019).

Denemede artan dozlarda $\mathrm{Zn}$ uygulamalarından kaynaklı verim artış oranlarının etkisinin yanısıra uygulanan farklı $\mathrm{Zn}$ formunun da önemli olduğu görülmüştür $(\mathrm{P}<0.05)$. Özellikle en düşük $\mathrm{Zn}$ uygulama dozu olan $0.2 \mathrm{mg} \mathrm{kg}^{-1}$ ' $\mathrm{da}$ kontrol uygulamasına göre ZnO'den kaynaklı yeşil aksam kuru madde verim artış1 \%11 iken bu değer $\mathrm{Zn}$-EDTA, $\mathrm{ZnCl}_{2}$ ve $\mathrm{ZnSO}_{4} .7 \mathrm{H}_{2} \mathrm{O}$ için sirasıyla \%139, \%101 ve \%49 olarak saptanmıştır (Çizelge 2). Çinkonun farklı formlarda kuru madde verimi üzerine etkisinin olduğu yapılan başka çalışmalarda da bildirilmiştir. Örneğin, Cevizcioğlu (2012), sera koşullarında buğdaya artan dozda ve farklı formlarda topraktan $\mathrm{Zn}$ uygulamış ve bitkinin kuru madde verimi üzerine olan etkisini saptamıştır. Çalışmada kontrol uygulamasına göre tüm formların kuru madde verimini önemli oranda arttırdığı ve topraktan artan dozlarda uygulanan $\mathrm{Zn}$ formlarından $\mathrm{Zn}$ EDTA'nın verim üzerinde en belirgin etkiye sahip olduğu buna karşılık en düşük etkinin ise $\mathrm{ZnO}$ formuna ait olduğunu bildirmiştir. Sera koşullarında yürütülen bir başka çalışmada farklı formlardan toprağa $\mathrm{Zn}$ uygulanmasıyla buğday bitkisinin tane veriminin kontrole göre $\mathrm{Zn}$-EDTA ile $\% 12$ artarken, $\mathrm{ZnSO}_{4}$ uygulaması ise \%10 artırdığı saptanmıştır (Modaihsh 1997). Benzer şekilde Taban ve ark. (1997), tarla koşullarında yürüttükleri çalışmada Zn-EDTA'nın buğdayın tane verimini $\mathrm{ZnSO}_{4}$ 'dan daha fazla arttırdığını bildirmişlerdir.

Çizelge 1. Artan dozlarda (Zn0: $0 \mathrm{mg} \mathrm{Zn} \mathrm{kg}{ }^{-1}$, Zn0.2: $0.2 \mathrm{mg} \mathrm{Zn} \mathrm{kg}^{-1}$, Zn1: $1 \mathrm{mg} \mathrm{Zn} \mathrm{kg}^{-1}$, Zn5: $\left.5 \mathrm{mg} \mathrm{Zn} \mathrm{kg}{ }^{-1}\right)$ ve farklı formlarda $\left(\mathrm{ZnO}_{2} \mathrm{ZnSO}_{4} .7 \mathrm{H}_{2} \mathrm{O}\right.$, $\mathrm{Zn}$-EDTA ve $\mathrm{ZnCl}_{2}$ ) $\mathrm{Zn}$ uygulamalarının mısırın yeşil aksam SPAD değerleri üzerine etkisi.

Table 1. Effects of increased doses (ZnO: $0 \mathrm{mg} \mathrm{Zn} \mathrm{kg}{ }^{-1}, \mathrm{Zn0.2:0.2} \mathrm{mg} \mathrm{Zn} \mathrm{kg-1,} \mathrm{Zn1:} 1 \mathrm{mg} \mathrm{Zn} \mathrm{kg}{ }^{-1}, \mathrm{Zn} 5: 5 \mathrm{mg} \mathrm{Zn} \mathrm{kg}^{-1}$ ) and different forms (ZnO, $\mathrm{ZnSO}_{4} .7 \mathrm{H}_{2} \mathrm{O}, \mathrm{Zn}$-EDTA and $\mathrm{ZnCl}_{2}$ ) of $\mathrm{Zn}$ applications on shoot SPAD values of maize.

\begin{tabular}{|c|c|c|c|c|c|}
\hline \multicolumn{6}{|c|}{ SPAD } \\
\hline $\begin{array}{c}\mathrm{Zn} \\
\left(\mathrm{mg} \mathrm{kg}^{-1}\right)\end{array}$ & $\mathrm{ZnO}$ & $\mathrm{ZnSO}_{4}$ & Zn-EDTA & $\mathrm{ZnCl}_{2}$ & Ortalama \\
\hline 0 & 34.07 & 34.07 & 34.07 & 34.07 & 34.07 \\
\hline 0.2 & 26.97 & 30.60 & 28.35 & 33.47 & 29.85 \\
\hline 1 & 21.23 & 32.65 & 30.60 & 26.57 & 27.76 \\
\hline 5 & 23.17 & 33.30 & 26.95 & 26.13 & 27.39 \\
\hline Ortalama & $26.36 c$ & $32.66 \mathrm{a}$ & $29.99 b$ & $30.06 \mathrm{ab}$ & \\
\hline$L S D_{(0.05)}$ & 4.69 & $\ddot{o . d}$. & 6.54 & 6.90 & \\
\hline
\end{tabular}

* ö.d : istatistiksel olarak önemli değil.

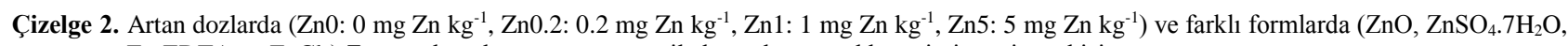
$\mathrm{Zn}$-EDTA ve $\mathrm{ZnCl}_{2}$ ) $\mathrm{Zn}$ uygulamalarının mısırın yeşil aksam kuru madde verimi üzerine etkisi.

Table 2. Effects of increased doses ( $\mathrm{Zn0}: 0 \mathrm{mg} \mathrm{Zn} \mathrm{kg}{ }^{-1}, \mathrm{Zn0} 0.2: 0.2 \mathrm{mg} \mathrm{Zn} \mathrm{kg}{ }^{-1}, \mathrm{Zn} 1: 1 \mathrm{mg} \mathrm{Zn} \mathrm{kg}{ }^{-1}, \mathrm{Zn5}: 5 \mathrm{mg} \mathrm{Zn} \mathrm{kg}^{-1}$ ) and different forms (ZnO, $\mathrm{ZnSO}_{4} .7 \mathrm{H}_{2} \mathrm{O}, \mathrm{Zn}$-EDTA and $\mathrm{ZnCl}_{2}$ ) of $\mathrm{Zn}$ application on shoot dry matter yield of maize.

\begin{tabular}{|c|c|c|c|c|c|}
\hline \multicolumn{6}{|c|}{ Yeşil Aksam Kuru Madde Verimi (g bitki ${ }^{-1}$ ) } \\
\hline $\begin{array}{c}\mathrm{Zn} \\
\left(\mathrm{mg} \mathrm{kg}^{-1}\right)\end{array}$ & $\mathrm{ZnO}$ & $\mathrm{ZnSO}_{4}$ & Zn-EDTA & $\mathrm{ZnCl}_{2}$ & Ortalama \\
\hline 0 & 1.05 & 1.05 & 1.05 & 1.05 & 1.05 \\
\hline 0.2 & 1.17 & 1.56 & 2.51 & 2.11 & 1.84 \\
\hline 1 & 2.26 & 2.85 & 3.11 & 3.09 & 2.83 \\
\hline 5 & 2.43 & 3.05 & 3.21 & 3.21 & 2.98 \\
\hline Ortalama & $1.73 \mathrm{c}$ & $2.13 b$ & $2.47 \mathrm{a}$ & $2.37 \mathrm{a}$ & \\
\hline$L S D_{(0.05)}$ & 0.29 & 0.39 & 0.57 & 0.62 & \\
\hline
\end{tabular}


Farklı formlarda uygulanan Zn'nun, misır ve buğday bitkisinin dışında diğer bitki türlerinde de benzer etkileri görülmüştür. Örneğin, Gülmezoğlu ve Aytaç (2016), aspir bitkisine topraktan ve yapraktan uygulanan Zn-EDTA ve $\mathrm{ZnSO}_{4} .7 \mathrm{H}_{2} \mathrm{O}$ formlarının verim ve $\mathrm{Zn}$ konsantrasyonu üzerine etkilerini belirlemek amacıyla yürüttükleri çalışmada, farklı Zn form ve uygulama metotlarının, bitkinin tane verimini kontrol uygulamasına göre önemli oranda arttırdığını bildirmişlerdir.

Tarla ve sera koşullarının yanısıra mısır bitkisine farklı formlardan uygulanan Zn'nun etkileri su kültürü koşullarında da araştırılmıştır. Örneğin, Rasheed ve ark. (2019), su kültürü koşullarında yaptıkları çalışmada, iki farklı mısır genotipi ile farklı $\mathrm{Zn}$ form ve uygulama metotlarının bitkinin kuru madde verimi ve $Z n$ konsantrasyonu üzerine etkilerini belirlemişler ve sonuç olarak doğrudan besin çözeltisine uygulanan Zn'nun yapraktan $\mathrm{Zn}$ uygulamasına göre bitkilerin kuru madde verimi üzerine daha etkili olduğunu, ayrıca $\mathrm{Zn}$-EDTA'nın $\mathrm{ZnSO}_{4}$ 'dan daha olumlu sonuç verdiğini bildirmişlerdir.

\section{2. Çinko uygulamalarının yeşil aksam Zn konsantrasyonu ve içeriği üzerine etkisi}

Artan dozlarda ve farklı formlarda $\mathrm{Zn}$ uygulamaları altında yetiştirilen mısır bitkisine ait yeşil aksam $\mathrm{Zn}$ konsantrasyonları Şekil 3'de verilmiştir. Elde edilen sonuçlara göre, $\mathrm{Zn}$ uygulamaları beklenildiği gibi bitkilerinin yeşil aksamındaki $\mathrm{Zn}$ konsantrasyonlarını önemli oranda arttırmıştır $(\mathrm{p}<0.005)$. Farklı $\mathrm{Zn}$ formlarından bağımsız olarak tüm saksılar için Zn'nun verilmediği uygulamada bitkinin yeşil aksam $\mathrm{Zn}$ konsantrasyonu $13 \mathrm{mg} \mathrm{kg}^{-1}$, Zn'nun 0.2 , 1 ve $5 \mathrm{mg} \mathrm{kg}^{-1}$ uygulandığ saksılarda ise sırasıyla 16,24 ve $50 \mathrm{mg} \mathrm{kg}^{-1}$ olduğu bulunmuştur. Kontrol uygulamasına göre artan dozda $\mathrm{Zn}$ uygulaması bitkilerin yeşil aksam $\mathrm{Zn}$ konsantrasyonunu arttırmış ve söz konusu artış oranları \%2 (ZnO-Zn0.2) ile \%327 (Zn-EDTA-Zn5) arasında değiştiği belirlenmiştir. Bu artışlarda Zn uygulama dozunun önemli olduğu buna karşıllk uygulanan gübre formlarının ise önemli bir farklılık yaratmadığ 1 görülmüştür (Şekil 3).

Kutman ve ark. (2010), Zn'ca fakir bir toprakta yürüttükleri bir çalışmada topraktan ve yapraktan $\mathrm{Zn}$ uygulamalarının makarnalık buğdayın tanesindeki $\mathrm{Zn}$ birikimi üzerine önemli bir etkisinin olduğunu; yapraktan veya topraktan Zn'nun uygulanması ile tanenin Zn konsantrasyonunun önemli derecede artmış olduğunu bildirmişlerdir. Mısır bitkisi ile su kültürü koşullarında tohumdan $\mathrm{Zn}$ uygulamalarını konu alan bir çalışmada ise, çözeltiden $\mathrm{Zn}$ uygulamasının yeşil aksam ve kök Zn konsantrasyonlarını arttırdığını bildirmiştir (Torun ve ark. 2016).

Bitkinin Zn alım karakteristiği açısından önemli bir parametre olan yeşil aksam $\mathrm{Zn}$ içeriğine $\mathrm{Zn}$ uygulama dozu ve formlarının etkisinin önemli olduğu görülmüștür. Örneğin, ZnO'in en düşük $\mathrm{Zn}$ uygulama dozu olan $0.2 \mathrm{mg} \mathrm{kg}^{-1} \mathrm{Zn}$ uygulaması altında $\mathrm{Zn}$ içeriği $16 \mu \mathrm{g} \mathrm{bitki}^{-1}$ iken bu değer $\mathrm{Zn}$-EDTA, $\mathrm{ZnCl}_{2}$ ve $\mathrm{ZnSO}_{4} .7 \mathrm{H}_{2} \mathrm{O}$ için sirasıyla 40,35 ve 24 $\mu \mathrm{g}$ bitki $^{-1}$ olarak saptanmıştır. Tüm uygulama dozlarında $\mathrm{Zn}$ alımı açısından en yüksek ve en etkin alımların, Zn-EDTA'da olduğu belirlenmiş, bunu sırasıyla $\mathrm{ZnCl}_{2}, \mathrm{ZnSO}_{4} .7 \mathrm{H}_{2} \mathrm{O}$ ve $\mathrm{ZnO}$ takip etmiştir (Şekil 4). Benzer bulgular Cevizcioğlu (2012) tarafindan vejetatif dönemde hasat edilen buğday bitkisinde de elde edilmiştir. Aynı çalışmada uygulanan tüm dozlarda bitki başına toplam $\mathrm{Zn}$ alımındaki en fazla artışın Zn-EDTA formunda olduğu, en az artışın ise $\mathrm{ZnO}$ formuna ait olduğu bildirilmiştir.

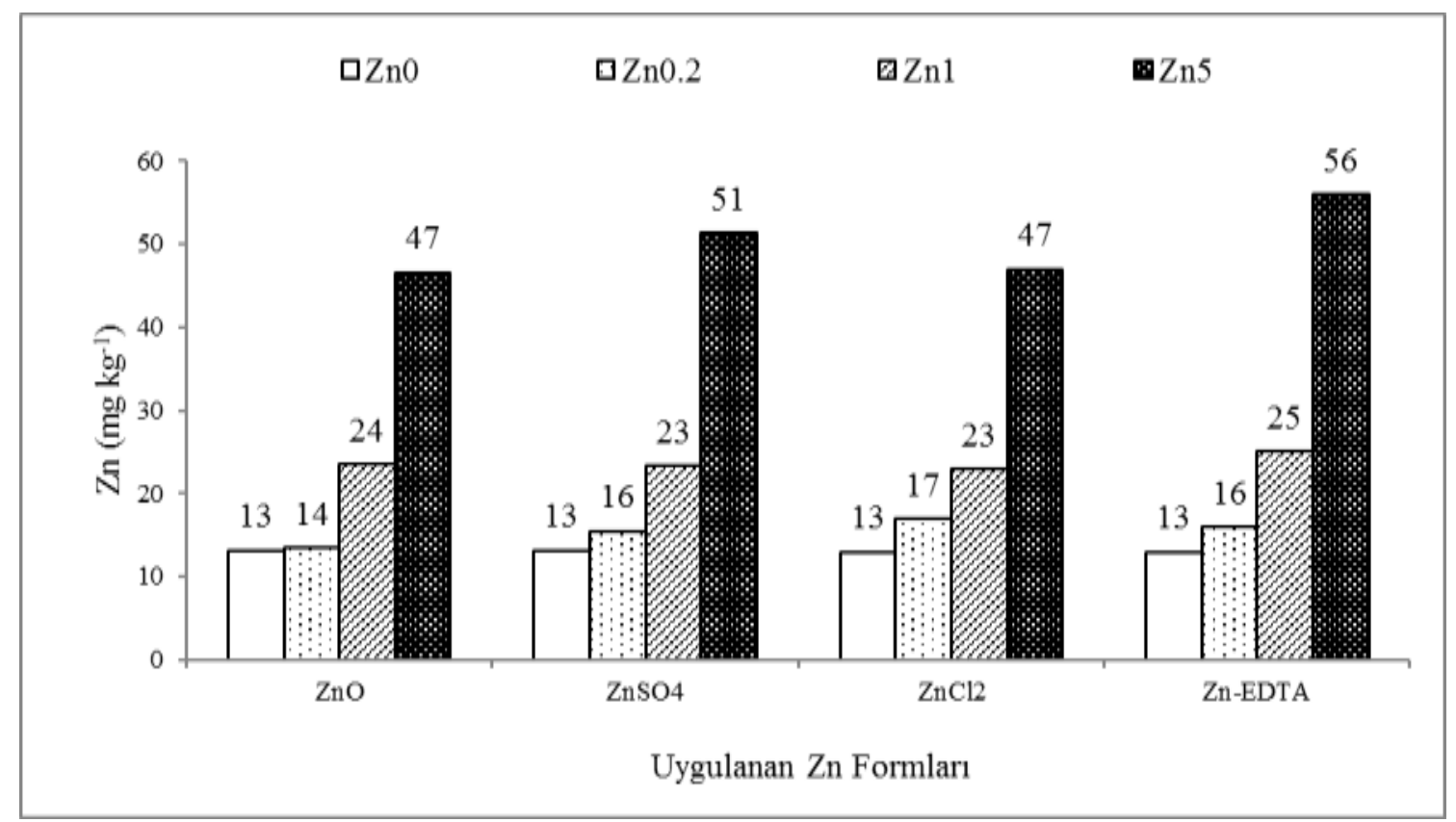

Şekil 3. Artan dozlarda ( $\left.\mathrm{Zn0}: 0 \mathrm{mg} \mathrm{Zn} \mathrm{kg}{ }^{-1}, \mathrm{Zn} 0.2: 0.2 \mathrm{mg} \mathrm{Zn} \mathrm{kg}^{-1}, \mathrm{Zn1}: 1 \mathrm{mg} \mathrm{Zn} \mathrm{kg}^{-1}, \mathrm{Zn} 5: 5 \mathrm{mg} \mathrm{Zn} \mathrm{kg}{ }^{-1}\right)$ ve farklı formlarda $\left(\mathrm{ZnO}_{2} \mathrm{ZnSO}_{4} .7 \mathrm{H}_{2} \mathrm{O}\right.$,

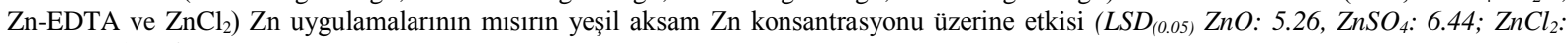
9.85; $\left.\mathrm{ZnCl}_{2}: 8.68\right)$.

Figure 3. Effects of increased doses ( $\mathrm{ZnO}: 0 \mathrm{mg} \mathrm{Zn} \mathrm{kg}^{-1}, \mathrm{Zn0} 0.2: 0.2 \mathrm{mg} \mathrm{Zn} \mathrm{kg}^{-1}, \mathrm{Zn1}: 1 \mathrm{mg} \mathrm{Zn} \mathrm{kg}{ }^{-1}, \mathrm{Zn} 5: 5 \mathrm{mg} \mathrm{Zn} \mathrm{kg}^{-1}$ ) and different forms (ZnO, $\mathrm{ZnSO}_{4} .7 \mathrm{H}_{2} \mathrm{O}$, $\mathrm{Zn}$-EDTA and $\mathrm{ZnCl}_{2}$ ) of $\mathrm{Zn}$ applications on shoot $\mathrm{Zn}$ concentration of maize (LSD(0.05) $\mathrm{ZnO}$ : 5.26, $\mathrm{ZnSO}_{4}: 6.44 ; \mathrm{ZnCl}_{2}: 9.85$; $\mathrm{ZnCl} 2: 8.68)$. 


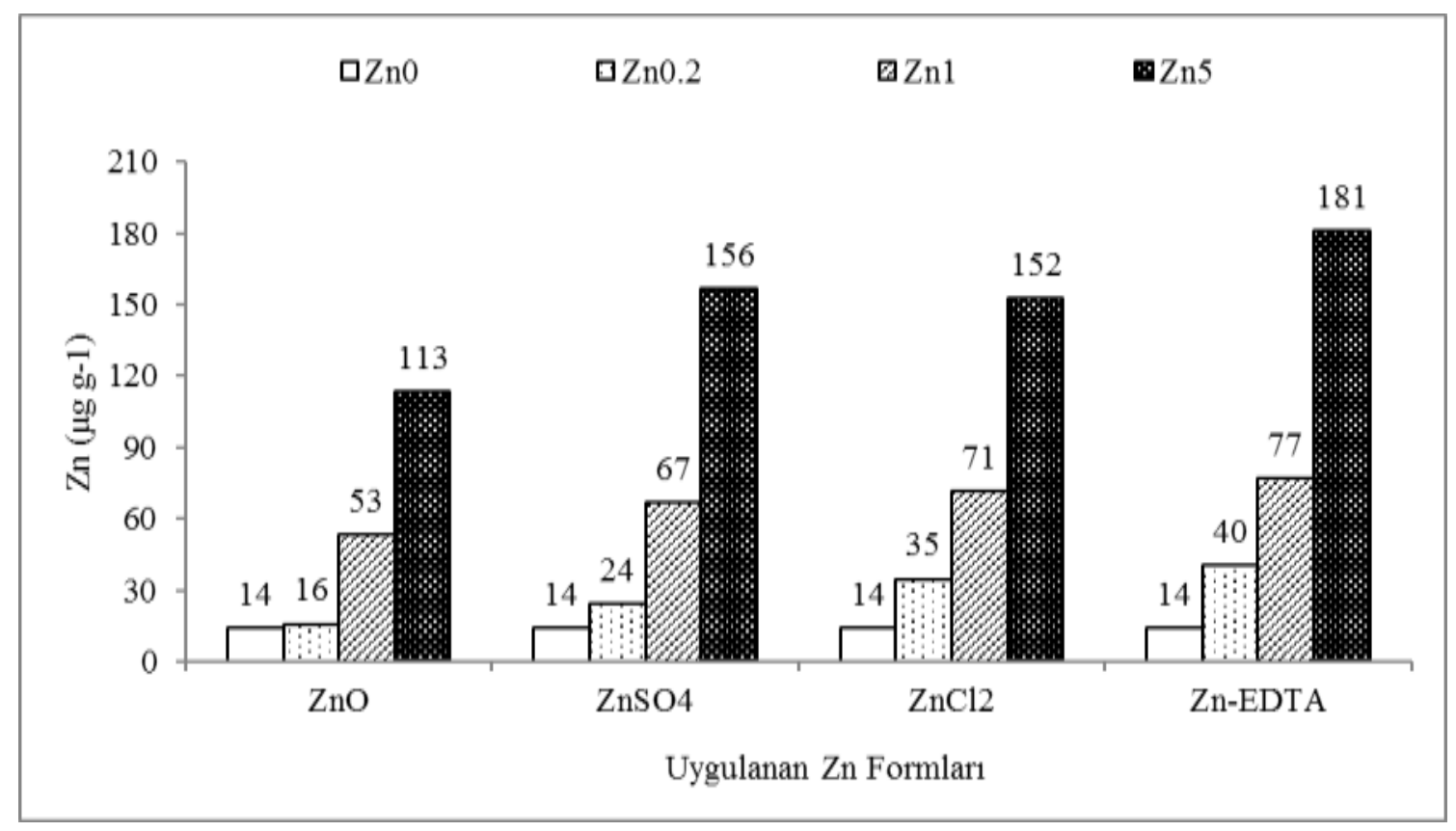

Şekil 4. Artan dozlarda (Zn0: $0 \mathrm{mg} \mathrm{Zn} \mathrm{kg}{ }^{-1}, \mathrm{Zn} 0.2: 0.2 \mathrm{mg} \mathrm{Zn} \mathrm{kg}^{-1}$, Zn1: $\left.1 \mathrm{mg} \mathrm{Zn} \mathrm{kg}^{-1}, \mathrm{Zn} 5: 5 \mathrm{mg} \mathrm{Zn} \mathrm{kg}{ }^{-1}\right)$ ve farklı formlarda $\left(\mathrm{ZnO}, \mathrm{ZnSO}_{4} .7 \mathrm{H}_{2} \mathrm{O}\right.$, $\mathrm{Zn}$-EDTA ve $\left.\mathrm{ZnCl}_{2}\right) \mathrm{Zn}$ uygulamalarının mısırın yeşil aksam $\mathrm{Zn}$ içeriği üzerine etkisi $\left(\operatorname{LSD}_{(0.05)} \mathrm{ZnO}: 14.54 ; \mathrm{ZnSO}\right.$ : 15 .62; $\mathrm{ZnCl} 2: 16,09 ; \mathrm{Zn}$ EDTA:20.03)

Figure 4. Effects of increased doses (ZnO: $\left.0 \mathrm{mg} \mathrm{Zn} \mathrm{kg}^{-1}, \mathrm{Zn0.2:} 0.2 \mathrm{mg} \mathrm{Zn} \mathrm{kg}^{-1}, \mathrm{Zn1:} 1 \mathrm{mg} \mathrm{Zn} \mathrm{kg}{ }^{-1}, \mathrm{Zn} 5: 5 \mathrm{mg} \mathrm{Zn} \mathrm{kg}^{-1}\right)$ and different forms (ZnO, $\mathrm{ZnSO}_{4} .7 \mathrm{H}_{2} \mathrm{O}, \mathrm{Zn}-\mathrm{EDTA}$ and $\mathrm{ZnCl}_{2}$ ) of $\mathrm{Zn}$ applications on shoot $\mathrm{Zn}$ concentration of maize ( $L \mathrm{SD}_{(0.05)} \mathrm{ZnO}: 14.54 ; \mathrm{ZnSO}_{4}: 15.62 ; \mathrm{ZnCl}: 16.09 ; \mathrm{Zn}$ EDTA:20.03).

\section{Sonuç}

Sera koşullarında gerçekleștirilen bu çalıșma sonucunda, toprağa yapılan $\mathrm{Zn}$ uygulamaları bitkinin sadece kuru madde verimlerini arttırmamış, aynı zamanda yeşil aksam $\mathrm{Zn}$ konsantrasyon ve içeriğinde de önemli artışlara yol açmıştır. Bu nedenle misır bitkisinde $\mathrm{Zn}$ noksanlığından kaynaklı verim kayıplarının önüne geçmek için özellikle Zn'ca fakir topraklarda ekim öncesinde $\mathrm{Zn}$ uygulamasının mutlaka yapılması gerekmektedir. Ayrıca gübre kullanım formu olarak sirasiyla; $\mathrm{Zn}$-EDTA, $\mathrm{ZnCl}_{2}$ ve $\mathrm{ZnSO}_{4} .7 \mathrm{H}_{2} \mathrm{O}$ 'n tercih edilmesi, $\mathrm{ZnCl}_{2}$ kullanımında tuzluluk problemi olmayan alanlarda kullanımına dikkat edilmesi gerektiği ancak Zn'nun topraktaki residüal etkisinin uzunluğu ve ekonomik koşullar düşünüldüğünde $\mathrm{ZnO}^{\prime}$ 'in de değerlendirilebilir nitelikte olduğu söylenebilir. Ancak, denemeye konu olan doz ve form uygulamalarının bitkinin tane verimi üzerine etkisini görmek için generatif dönemi de içine alan çalışmaların yapılması gerekmektedir.

\section{Kaynaklar}

Aktaş H, Abak K, Öztürk L, Çakmak İ (2006) The effect of zinc on growth and shoot concentrations of sodium and potassium in pepper plants under salinity stress. Turkish Journal Agriculture Forestry 30: 407-412.

Alloway BJ (2009) Soil factors associated with zinc deficiency in crops and humans. Environmental Geochemistry and Health 31(5): 537548.

Bagci SA, Ekiz H, Yilmaz, A, Cakmak, I (2007) Effects of zinc deficiency and drought on grain yield of field-grown wheat cultivars in Central Anatolia. Journal of Agronomy \& Crop Science 193: 198-206.

Bouyoucos GJ (1951) A Recalibration of hydrometer for making mechanical analysis of soil. Agronomy Journal 43: 434-437.
Cakmak I (2008) Enrichment of cereal grains with zinc: agronomic or biofortification. Plant Soil 302(1-2): 1-17.

Cakmak I, Kalayci M, Kaya Y, Torun AA, Aydin N, Wang Y, Arisoy Z, Erdem H, Yazici A, Gokmen O, Ozturk L, Horst WJ (2010) Biofortification and localization of zinc in wheat grain. Journal of Agricultural \& Food Chemistry 58: 9092-9102.

Cakmak I, Kutman UB (2018) Agronomic biofortification of cereals with zinc: A review. European Journal of Soil Science 69: 172-180.

Cevizcioğlu Ö (2012) Değişik çinko formlarının ekmeklik buğdayda verim ve tane çinko konsantrasyonu üzerine etkisi. Yüksek Lisans Tezi, Namık Kemal Üniversitesi Fen Bilimleri Enstitüsü, Tekirdağ.

Çağlar KÖ (1949) Toprak Bilgisi. Ankara Üniversitesi. Yayınları No: 10, Ankara.

Dhaliwal SS, Sadana US, Manchanda JS, Dhadli HS (2009) Biofortification of wheat grains with zinc $(\mathrm{Zn})$ and iron $(\mathrm{Fe})$ in typic ustochrept soils of Punjab. Indian Journal of Fertilizers 5: 13-16.

Dhaliwal SS, Ram H, Shukla AK, Mavi GS (2019) Zinc biofortification of bread wheat, triticale, and durum wheat cultivars by foliar zinc fertilization. Journal of Plant Nutrition 42(8): 813.

Erdem H (2011) Silajlık mısır çeşitlerinin verim ve kalitesine çinko gübrelemesinin etkilerinin belirlenmesi. Gaziosmanpaşa Üniversitesi Ziraat Fakültesi Dergisi 28(2): 199-206.

FAO (2018) FAO Statistical Year. http://faostat.fao.org. Erişim 15 Mart 2018.

Genç Y, McDonald GK, Graham RD (2004) Differential expression of zinc efficiency during the growing season of barley. Plant and Soil 263: 273-282.

Graham RD, Welch RM (1996) Breeding for staple-food crops with high micronutrient density: Working Papers on Agricultural Strategies for Micronutrients, No.3. International Food Policy Institute, Washington DC. 
Grewal HS, Williams R (1999) Alfalfa genotypes differ in their ability to tolerate zinc deficiency. Plant and Soil 214: 39-48.

Gülmezoğlu N, Aytaç, Z (2016) Farklı çinko uygulamalarının aspir bitkisinin verimi ve çinko alımı üzerine etkisi. Toprak Su Dergisi 5(2): 11-17.

Güneş A, İnal A, Alpaslan M, Çıkılı Y (1999) Effect of salinity on phosphorus induced zinc deficency in pepper (Capsicum annuum L.) Plants. Agriculture and Forestry 23: 459-464.

Hacısalihoğlu G, Öztürk L, Çakmak İ, Welch RM, Kochian L (2004) Genotypic variation in common bean in response to zinc deficiency in calcareous soil. Plant and Soil 259: 71-83.

Hotz C, Brown KH (2004) Assessment of the risk of zinc deficiency in populations and options for its control. Food Nutrition Bulletin 25: 94-204.

Jackson ML (1959) Soil chemical analysis. Englewood Cliffs, New Jersey.

Khan HR, McDonald GK, Rengel Z (1998) Chickpea genotypes differ in their sensitivity to Zn deficiency. Plant and Soil 198: 11-18.

Kutman UB, Yildiz B, Ozturk L, Cakmak I (2010) Biofortification of durum wheat with zinc through soil and foliar applications of nitrogen. Cereal Chemistry 87: 1-9.

Lindsay WL, Norwell WA (1978) Development of a DTPA Soil test for $\mathrm{Zn}, \mathrm{Fe}, \mathrm{Mn}$ and $\mathrm{Cu}$. Soil Science Society of America: Proceedings 42: 421-428.

Martens DC, Westermann DT (1991) Fertilizer applications for correcting micronutrient deficiencies. In: Mortvedt JJ, Cox FR, Shuman LM, Welch RM (eds) Micronutrients in Agriculture. SSSA Book Series No. 4. Madison, WI. s. 549-592.

Modaihsh AS (1997) Foliar application of chelated and non-chelated metals for supplying micronutrients to wheat grown on calcareous soil. Experimental Agriculture 33: 237-245.

Mortvedt JJ (1991) Micronutrient fertilizer technology. In: Mortvedt JJ, Cox FR, Shuman LM, Welch RM (eds) Micronutrients in Agriculture. SSSA Book Series No. 4. Madison, WI. s. 89-112.

Ortiz-Monasterio JI, Palacios-Rojas N, Meng E, Pixley K, Trethowan R, Pena RJ (2007) Enhancing the mineral and vitamin content of wheat and maize through plant breeding. Journal Cereal Science 46 (3): 293-307.

Özer MS (1999) Harran ovası koşullarında değişik mısır genotiplerinin çinko gübrelemesine reaksiyonları ve çinko yetersizliğine dayanıklı genotiplerin seçimi. Doktora Tezi, Çukurova Üniversitesi, Adana.

Özgüven N, Katkat AV (2001) Artan miktarlarda uygulanan çinkonun misır bitkisinin verim ve çinko alımı üzerine etkisi. Uludağ Üniversitesi Ziraat Fakültesi Dergisi 15: 85-97.
Pandey N, Pathak GC, Sharma CP (2006) Zinc is critically required for pollen function and fertilisation in lentil. Journal of Trace Elements in Medicine and Biology 20: 89-96.

Quijano-Guerta, C, Kırk GJD, Portugal AM, Bartolome VI, Mclaren GC (2002) Tolerance of Rice Germplasm to Zinc Deficiency. Field Crops Research 76: 123-130.

Rasheed N, Maqsood MA, Aziz T, Rehman MZU, Bilal HM, Ayub MA, Irfan M, Sanaullah M (2019) Zinc application methods affect its accumulation and allocation pattern in maize grown in solution culture. International Journal of Agriculture and Biology 21: 11971204.

Signorell C, Zimmermann MB, Cakmak I, Wegmuller R, Zeder C, Hurrell R, Aciksoz SB, Boy E, Tay F, Frossard E, Moretti D (2019) Zinc absorption from agronomically biofortified wheat is similar to post-harvest fortified wheat and is a substantial source of bioavailable zinc in humans. The Journal of Nutrition 149: 840846.

Singh B, Natesan SKA, Sing BK, Usha K (2005) Improving zinc efficiency of cereals under zinc deficiency. Current Science 88: 1.

Taban S, Alpaslan M, Güneş A, Aktaş M, Erdal İ, Eyüpoğlu H, Baran İ (1997) Değişik şekillerde uygulanan çinkonun buğday bitkisinde verim ve çinkonun biyolojik yarayışlılığı üzerine etkisi. 1. Ulusal Çinko Kongresi. Cilt 1, Eskişehir, s. 147-156.

Torun B, Çakmak Ö, Özbek H, Çakmak İ (1998) Çinko eksikliği koşullarında yetiştirilen değişik tahıl türlerinin ve çeşitlerinin çinko eksikliğine karşı duyarlılığının belirlenmesi. I Ulusal Çinko Kongresi (Tarım, Gıda ve Sağlık) Cilt 1, Eskişehir, s. 363-369.

Torun AA, Er A, Erdem H, Torun B (2016) Tohuma çinko uygulama metodunun su kültürü koşullarında mısırın kuru madde verimi ve çinko konsantrasyonu üzerine etkisinin belirlenmesi. Toprak $\mathrm{Su}$ Dergisi 5(2): 42-51.

Torun AA, Duymuş E, Erdem H, Torun MB (2019) Effects of Zn applications on dry matter yield and mineral nutrient uptake of corn and wheat crops in two different regions of soils with zinc deficiency. Turkish Journal of Agriculture - Food Science and Technology 7(9): 1382-1386.

Welch RM, Graham RD (2004) Breeding for micronutrients in staple food crops from a human nutrition perspective. Journal of Experimental Botany 55: 353-364.

White JG, Zasoskı RJ (1999) Mapping soil micronutrients. Field Crop Research 60: 11-26.

Yağmur B, Ceylan Ş, Yoldaş F, Oktay M (2002) Çinko katkılı ve katkısız kompoze gübrelerin sakız kabağı (Cucurbita Pepo cv.) yetiştiriciliğinde verim ve bazı verim kriterlerine etkisi. Ege Üniversitesi Ziraat Fakültesi Dergisi 39(1): 111-117. 